\title{
Functional, Diagnostic and Therapeutic Aspects of Gastrointestinal Hormones
}

\author{
Monjur Ahmed ${ }^{\mathrm{a}, \mathrm{b}, \mathrm{c}}$, Sarah Ahmed ${ }^{\mathrm{a}, \mathrm{b}}$
}

\begin{abstract}
Gastrointestinal (GI) hormones are essential to many physiologic functions in our body. They have many GI and extra-GI functions. Some of the functions of these hormones, which have GI and extra-GI sources, are still unknown. Specific GI hormones can affect the brain to control food intake, while others can proliferate normal and neoplastic tissue when their receptors are expressed in certain neoplasms. GI hormones also have many diagnostic and therapeutic roles. Physiologic and pathophysiologic aspects as well as the diagnostic and therapeutic values of GI hormones are elaborated in this review.
\end{abstract}

Keywords: Gastrointestinal hormones; Functions of gut hormones; Diagnostic roles of gut hormones; Therapeutic roles of gut hormones; Effect of gut hormones on neoplastic proliferations

\section{Introduction}

Gastrointestinal (GI) hormones are a group of peptides secreted by the endocrine cells, also known as endocrinocytes, in different parts of the GI mucosa and pancreas [1]. Most of these are secreted after a meal, after which they are released into blood and circulate to different organs. Some of the functions of GI hormones on the GI tract, pancreas and nervous system include the regulation of secretion, digestion, absorption, GI motility, appetite as well as trophic effects on GI mucosa and certain neoplasms [2]. The GI hormones are first classified and then each hormone is discussed separately.

\section{Classification of GI Hormones}

Based on chemical structure, GI hormones can be divided into

Manuscript submitted September 6, 2019, accepted September 23, 2019

aSidney Kimmel Medical College, Thomas Jefferson University, Philadelphia, PA 19107, USA

${ }^{b}$ Both authors contributed equally to write the manuscript.

${ }^{\mathrm{c} C o r r e s p o n d i n g ~ A u t h o r: ~ M o n j u r ~ A h m e d, ~ S i d n e y ~ K i m m e l ~ M e d i c a l ~ C o l l e g e, ~}$ Thomas Jefferson University, 132 South 10th Street, Main Building, Suite 468, Philadelphia, PA 19107, USA. Email: monjur.ahmed@jefferson.edu

doi: https://doi.org/10.14740/gr1219 the following groups as shown in Table 1 [3].

Excluding the above hormones, there are certain hormones which are not mentioned in the above classification. These include gastrin-releasing peptide (GRP), glucagon-like peptide-1 (GLP-1), glucagon-like peptide-2 (GLP-2), gastric leptin, oxyntomodulin and uroguanylin.

\section{Gastrin}

Gastrin is secreted mainly from $\mathrm{G}$ cells of the gastric antrum. Occasionally, G cells can be found in duodenum [4], pancreas [5] and pituitary gland [6]. Gastrin is released into the circulation in response to gastric antral distension, food containing aromatic amino acids, small peptides, vagal stimulation, hypercalcemia and GRP [7]. Gastrin secretion is inhibited by increased acidity of the stomach ( $\mathrm{pH} 3$ or below), low-level gastric distension and somatostatin [8]. Gastrin works on the parietal cells to stimulate acid secretion and has a trophic effect on the oxyntic mucosa [9]. The precursor of gastrin is progastrin which is synthesized and stored in the secretory granules of antral $\mathrm{G}$ cells. Three forms of gastrin are released into the circulation after processing (amidation and cleavage): G-34 or big gastrin, G-17 or little gastrin and G-14 or small gastrin [10]. G-34 and G-17 are bioactive. Most of the G-17 are produced after cleavage from G-34.

Most of the gastrin released following food intake is G-17. But as G-17 is quickly cleared from the circulation, most of the gastrin seen in the circulation during the fasting state is G-34. Both G-17 and G-34 can stimulate the enterochromaffin-like (ECL) cells of the oxyntic mucosa to synthesize and release histamine, as well as parietal cells to secrete acid through the cholecystokinin B receptors (CCKBRs, formerly known as gastrin/CCK2 receptors). Histamine binds to $\mathrm{H} 2$ receptors on parietal cells and induces acid secretion. Gastrin can increase both ECL and parietal cell mass. Parietal cells or oxyntic cells are present throughout the length of gastric glands located in gastric fundus and gastric body. They secrete hydrochloric acid (keeping gastric $\mathrm{pH}$ between 1.5 and 3.5) and intrinsic factor which aids the absorption of vitamin B12 from the terminal ileum. Chief cells or zymogenic cells are present in the basal part of gastric glands and they secrete inactive pepsinogen (PG) which becomes active pepsin on exposure to acid. Pepsin partially digests protein into peptides only in the acidic medium. Chief cells are activated by gastrin, secretin, vasoactive intestinal peptide (VIP), acetylcholine and epinephrine. The gastric corpus chief cell mass is decreased in patients with 
Table 1. Classification of GI Hormones

\begin{tabular}{ll}
\hline 1. Gastrin-cholecystokinin family & Gastrin and cholecystokinin \\
2. Secretin family & Secretin, glucagon, glicentin, VIP and GIP \\
3. Somatostatin family & Somatostatin \\
4. Motilin family & Motilin, gherlin, obestatin \\
5. Substance P & Substance P \\
\hline
\end{tabular}

GI: gastrointestinal; GIP: gastric inhibitory peptide; VIP: vasoactive intestinal peptide.

multifocal atrophic gastritis (MAG), i.e. foci of gastric atrophy and intestinal metaplasia starting at the junction of gastric corpus and antrum and extending into the adjacent mucosa of both with time [11]. In gastric antral atrophy, there is a decrease in serum concentration of G-17 which is mainly secreted by antral glands. Gastrin has trophic effect on gastric, small bowel and probably colonic mucosa [12]. It also increases gastric mucosal blood flow, gastric motility, and to a lesser extent, small intestinal and gall bladder motility [13]. As mentioned before, $\mathrm{G}$ cells can be present in the duodenal wall and pancreatic islet cells, where patients can develop a gastrinoma. Patients with gastrinoma secrete huge amount of gastrin leading to severe hypergastrinemia. Of the gastrinomas, $85-90 \%$ are located in the gastrinoma triangle bounded superiorly by the cystic duct and common bile duct, inferiorly by the second and third part of duodenum and medially by the neck and body of pancreas [14]. Of gastrinomas, 40-50\% occur in the duodenal wall. Various imaging studies (computerized axial tomography, magnetic resonance imaging and octreotide scan) and endoscopic ultrasound can detect the location of gastrinomas $[15,16]$. Other causes of significant hypergastrinemia (serum gastrin $>150$ $\mathrm{pg} / \mathrm{mL}$ ) include $\mathrm{H} 2$ blocker and proton pump inhibitor therapy, $H$. pylori infection, chronic atrophic gastritis, renal failure, gastric outlet obstruction, retained gastric antrum, antral G cell hyperplasia and vagotomy [17].

Secretin suppression test is a provocative test used to evaluate hypergastrinemia suspected of gastrinoma. Normally, secretin suppresses the release of serum gastrin. However, in a gastrinoma (Zollinger-Ellison syndrome), there is a paradoxical rise of serum gastrin after intravenous administration of exogenous secretin $0.4 \mu \mathrm{g} / \mathrm{kg}$ as a single dose [18].

Pentagastrin is a synthetic pentapeptide analogue of natural gastrin comprised of the first five amino acids of gastrin. Like gastrin, it can stimulate the secretion of acid, pepsin and intrinsic factor. Pentagastrin was studied to investigate the secretory response of acid and pepsin in peptic ulcer disease. In response to the administration of pentagastrin, the secretion of acid and pepsin was markedly higher in duodenal ulcers, slightly higher in pyloric ulcers and slightly lower in gastric ulcers [19]. Men secreted more acid per kilogram of body weight than women both in healthy individuals and patients with peptic ulcer disease [20].

The pentagastrin stimulation test is also used in the early diagnosis of medullary carcinoma of the thyroid gland (MCT) in the presence of an equivocal or slightly high serum calcitonin level. Pentagastrin binds to CCKBRs on parafollicular cells of MCT and increases serum calcitonin level by $>100 \mathrm{pg} /$ $\mathrm{mL}[21]$. This test is also used in determining the necessity of surgical resection of MCT [22] and investigating any residual MCT after surgery [23]. Pentagastrin stimulation test can also be used for assessment of completeness of vagotomy by measuring peak acid output (PAO) of the stomach [24].

\section{Cholecystokinin (CCK)}

CCK is a peptide hormone secreted by the enteroendocrine I cells located within the crypts of Lieberkuhn of the duodenum and jejunum in response to partially digested food (amino acids, proteins and fats). It stimulates gallbladder contraction, pancreatic enzyme secretion and bowel motility, inhibits gastric emptying, potentiates insulin secretion and has trophic effects on the intestinal mucosa and pancreas [1]. CCK suppresses hunger by inhibiting expression of orexigenic peptides in the hypothalamus and preventing stimulation of specialized neurons by ghrelin. It also induces satiety by interacting with CCK-1 receptors in the hind brain [25]. The diagnostic and therapeutic roles of CCK are as follows.

1) Diagnosis of gall bladder dyskinesia: Sometimes patients present with typical biliary symptoms but show no evidence of gallstones on ultrasonography. In those cases, the gall bladder ejection fraction is measured by using provocative technetium labeled hepatic iminodiacetic acid (HIDA) scan with CCK. Patients with gall bladder ejection fraction of $<$ $40 \%$ (biliary dyskinesia) are offered cholecystectomy. In one study, $79 \%$ of those patients who underwent cholecystectomy improved or remained symptom-free after a median follow-up of more than 2 years [26].

2) Identification of ampulla of Vater: On rare occasions, it can be difficult to visualize or localize the major papilla during endoscopic retrograde cholangiopancreatography (ERCP). In such a case, CCK is injected intravenously to cause gall bladder contraction, which helps in identifying the major papilla as bile flows through the bile duct into the duodenum.

3) Clearance of common bile duct (CBD) stones: CCK has also been used to facilitate endoscopic clearance of large CBD stones. In one study, CCK was given intravenously near the start of extracorporeal shockwave lithotripsy (ESWL) and ERCP was performed $4 \mathrm{~h}$ later. Use of CCK showed a significantly higher rate of stone removal, reduced use of mechanical lithotripsy and higher clearance rate of extremely large $(>3 \mathrm{~cm})$ stones [27].

\section{Secretin}

Secretin is a polypeptide hormone secreted by the enteroen- 
docrine $\mathrm{S}$ cells located within the crypts of Lieberkuhn in the duodenum and proximal jejunum in response to the presence of acidic $\mathrm{pH}$ in the lumen [28]. It stimulates pancreatic acinar cells to secrete water and bicarbonate to be drained through the pancreatic duct into the duodenum. As a result, the acidic environment is quickly neutralized. Secretin also inhibits gastrin secretion to stop acid secretion into the stomach, and delays gastric emptying [29]. Secretin is used in two diagnostic tests.

1) Secretin test: It is used in the evaluation of pancreatic exocrine insufficiency. Intravenous secretin $0.2 \mu \mathrm{g} / \mathrm{kg}$ is given as a single dose and then duodenal fluid is collected at baseline and every $15 \mathrm{~min}$ for an hour. This can be done by the traditional secretin test in which an oroduodenal collection tube (Dreiling tube) with gastric and duodenal ports is used [30] or by the endoscopic secretin test in which endoscopically placed Dreiling tube or Liguory tube is used [31]. Fluid is analyzed for bicarbonate concentration, bicarbonate output and volume. A peak bicarbonate concentration of less than $80 \mathrm{mEq} / \mathrm{L}$ is diagnostic of exocrine pancreatic insufficiency.

2) Secretin-enhanced magnetic resonance cholangiopancreatography (MRCP): It has been found to be useful in the diagnosis of early chronic pancreatitis, exocrine pancreatic insufficiency [32] and pancreatic divisum [33].

$\mathrm{CCK}$ and secretin are also called enterogastrones as they are secreted by the duodenal mucosa in response to lipid ingestion, and inhibit gastric acid secretion and motility [34].

\section{Somatostatin}

Somatostatin (growth hormone release inhibiting hormone) is an inhibitory cyclic tetradecapeptide released from the neuroendocrine neurons of hypothalamus and neuroendocrine delta (D) cells of the islets of Langerhans in the pancreas and GI tract. D cells are present throughout the GI tract but mostly concentrated in the gastric antrum and fundus, and colon [35]. Somatostatin has a short half-life of $1-3 \mathrm{~min}$. It is initially released after ingestion of a meal and is further released when the plasma levels of glucose, amino acids and fatty acids are increased. It is also stimulated by glucagon, insulin deficiency, secretin, cholecystokinin and VIP. The cholinergic pathway inhibits the secretion of somatostatin. Somatostatin (meaning stagnation of a body) acts as a universal endocrine offswitch. It inhibits the release of growth hormone (GH), thyrotropin (TSH) and corticotropin $(\mathrm{ACTH})$ from the pituitary gland. In the GI system, it inhibits the secretion of gastrin, cholecystokinin, secretin, VIP, insulin and glucagon. As a result, it decreases gastric, pancreatic and intestinal secretion including pancreatic enzymes and bicarbonate secretion, GI and gallbladder motility, and the intestinal absorption of fluid and electrolytes. In addition, it selectively reduces portal and splanchnic blood flow, and inhibits the growth of normal gut mucosa and pancreas [36]. Due to its very short half-life, few analogues of somatostatin have been developed for diagnostic and therapeutic purposes. These include octreotide, lanreotide and vapreotide. Of these three agents, octreotide is the most widely used in various diagnostic and therapeutic endeavors. Octreotide is an octadecapeptide, a synthetic analogue of so- matostatin with a half-life of $113 \mathrm{~min}$. Although it mimics the actions of natural somatostatin, it is a stronger inhibitor of insulin, glucagon and GH compared to somatostatin.

\section{Diagnostic Use of CCK}

Octreotide scan, also known as somatostatin receptor scintigraphy (SRS), is a radionuclide scan used to detect and monitor the progress of treatment of neuroendocrine tumors that have somatostatin receptors. Octreotide radiolabeled with the radioactive tracer indium-111 is injected into the vein and then the radioactivity is measured by a radiation measuring device (gamma camera). Octreotide scan is positive in $\mathrm{GH}$ producing pituitary adenoma, gastrinoma (sensitivity 60-90\%), carcinoid tumor (sensitivity 80-100\%), paragangliomas, medullary carcinoma of thyroid (sensitivity 50-70\%), small-cell lung cancer, breast cancer (sensitivity 75\%), neuroblastoma, pheochromocytoma, meningioma, well-differentiated astrocytoma, metastatic Merkel cell tumor and in various autoimmune and granulomatous disorders like Graves' disease, DeQuervain's thyroiditis, Wegener's granulomatosis, sarcoidosis and tuberculosis [37].

\section{Therapeutic Uses of CCK}

\section{Esophageal variceal bleeding}

Octreotide infusion is given in esophageal variceal bleeding, a life-threatening complication of chronic liver disease with portal hypertension with a high mortality of at least $20 \%$. This complication occurs due to variceal rupture from high portal pressure and portal/systemic pressure gradient exceeding 12 $\mathrm{mm} \mathrm{Hg}$. Octreotide ameliorates portal pressure by decreasing the secretion of splanchnic vasodilating hormones like VIP and glucagon [38], leading to mesenteric vasoconstriction and increased splanchnic vascular resistance. It is an effective adjunctive therapy in the control of acute esophageal variceal bleed [39]. Another study showed that octreotide enhanced portal pressure reduction induced by propranolol in cirrhosis of liver [40].

\section{Chronic intestinal pseudo-obstruction (CIPO)}

Octreotide given subcutaneously at night (before going to bed) 2 - $3 \mathrm{~h}$ after a meal has been shown to induce phase III migratory motor complexes (MMC) in idiopathic CIPO [41] and CIPO due to systemic sclerosis [42]. Octreotide reduces bacterial overgrowth, nausea and abdominal pain in these categories of patients. In another study, administration of octreotide was helpful in improving enteral tolerance in total parental nutrition (TPN)-dependent children with CIPO [43].

\section{Pancreatic fistula}

Octreotide has a therapeutic role in pancreatic ascites. The hor- 
mone significantly decreases pancreatic exocrine secretion and the volume of fistula output, aiding the healing of pancreatic fistulas [44]. In this setting, octreotide is given subcutaneously 2 - 3 times a day.

\section{Refractory and secretory diarrhea}

As octreotide improves intestinal absorption and decreases gastric, intestinal and pancreatic secretion, it has been used in refractory diarrhea [45]. Octreotide is also very effective in controlling secretory diarrhea secondary to GI endocrine tumors (carcinoid tumor, VIPomas), short bowel syndrome (SBS), intestinal graft vs. host disease, diabetes mellitus, intestinal infections in acquired immunodeficiency syndrome, dumping syndrome, and patients receiving radiation therapy [46] or chemotherapy [47].

\section{Carcinoid crisis}

Carcinoid crisis generally occurs in patients known to have carcinoid syndrome and is a life-threatening complication. It is characterized by sudden onset of flushing of face and upper body, severe hypotension and sometime bronchospasm with wheezing due to the release of abundant amounts of vasoactive and bioactive amines and peptides (serotonin, histamine, dopamine, VIP and catecholamines) from the tumor. The crisis can be triggered by stress, chemotherapy, anesthesia or manipulation of the tumor by biopsy or surgery. Peri-operative and intra-operative octreotide ( 25 - $500 \mu \mathrm{g}$ intravenously) can successfully prevent and treat carcinoid crisis [48]. Monthly depot injection of octreotide or lanreotide can control the symptoms of carcinoid syndrome [49].

\section{Hepatorenal syndrome (HRS)}

HRS is characterized by functional renal failure due to renal vasospasm. It is a serious complication of liver cirrhosis with ascites, fulminant hepatitis and severe alcoholic hepatitis. It occurs in the presence of portal hypertension, splanchnic vasodilatation and a fall in mean arterial pressure. It is characterized by progressive oliguria, progressive rise in serum creatinine $(>1.5 \mathrm{mg} / \mathrm{dL})$, very low urine sodium $(<10$ $\mathrm{mmol} / \mathrm{L}$ ), hyponatremia and absence of proteinuria [50]. It carries a poor prognosis and liver transplantation remains the treatment of choice [51]. Octreotide/midodrine treatment has been shown to improve serum creatinine and 30-day mortality [52].

\section{VIPoma}

VIPoma is a rare (incidence 1 per 10 million individuals per year) neuroendocrine tumor generally located in the tail of the pancreas. Also known as Verner-Morrison syndrome or pancreatic cholera, it secretes VIP and causes massive wa- tery diarrhea (>700 mL/day), hypokalemia and achlorhydria (WDHA). Octreotide can successfully reduce diarrhea and the tumor bulk [53], and has been used to treat metastatic VIPoma in combination with chemotherapy and surgery [54]. Octreotide is also very effective in VIPoma crisis, which is characterized by severe secretory and refractory diarrhea, and severe hypotension [55].

\section{Acromegaly}

Acromegaly is caused by a GH-secreting tumor in the pituitary gland. $\mathrm{GH}$ stimulates secretion of somatomedin $\mathrm{C}$ or insulinlike growth factor 1 (IGF-1) from the liver. IGF-1 is the mediator of peripheral somatic effects of GH. Octreotide has been used as an adjuvant therapy in acromegaly. It can reduce the size of the tumor in $25 \%$ of cases, and suppress GH secretion to lead to normal IGF-1 levels in $25-50 \%$ of cases [56].

\section{Sulfonylurea poisoning}

Octreotide in combination with intravenous dextrose has been used in symptomatic intentional sulfonylurea overdose. Sulfonylurea increases insulin secretion by stimulating beta cells of islets of Langerhans of pancreas and also decreases hepatic glucose production. Thus sulfonylurea may cause profound hypoglycemia. Generally, 50\% dextrose is given intravenously to increase blood glucose, but it can cause hyperglycemia with consequent insulin secretion and subsequent rebound hypoglycemia. Octreotide inhibits $\beta$ cells to secrete insulin and can prevent this rebound hypoglycemia [57].

\section{Motilin}

Motilin is a polypeptide hormone (22 amino acids) secreted from the Mo endocrine cells present in the crypts of Lieberkuhn of the duodenum and jejunum [58]. This hormone is such named as it stimulates the motility of the GI tract. Motilin is secreted cyclically every $90-120$ min during the fasting period, and initiates 5 - $10 \mathrm{~min}$ of strong peristaltic phase III contraction of migrating myoelectric complex (MMC) also called "intestinal housekeeper" which starts from the gastric antrum and forcefully propels undigested gut contents and bacteria into the colon [59]. Motilin also stimulates pepsin secretion from the chief cells of the stomach [60] and induces gall bladder emptying [61].

Erythromycin is a motilin receptor agonist and stimulates GI motor activity [62]. It improves gastric emptying and symptom score in patients with gastroparesis [63] and has an off-label indication for the treatment of gastroparesis [64].

\section{Ghrelin or Lenomorelin}

Ghrelin or lenomorelin is a peptide hormone produced and secreted by the ghrelinergic cells mainly in the gastric fundus 
and in small amounts in the small intestine, colon, pancreas, lungs and brain [65]. Also called the "hunger hormone", ghrelin induces intense hunger; its serum level increases during fasting and just before eating indicating that ghrelin may be responsible for the "hunger pangs". Serum ghrelin level becomes normal in the post-prandial state. It stimulates appetite (orexigenic), GH secretion from the pituitary gland and fat deposition (adipogenic) in the body. It also plays a role in 1) glucose metabolism by inhibiting insulin secretion and controlling glycogenolysis and gluconeogenesis; 2) bone metabolism by causing the differentiation and proliferation of osteoblasts, and preventing osteoporosis; 3) decreasing sarcopenia by causing the differentiation and fusion of muscles thereby preventing muscle atrophy; and 4) cardioprotection by decreasing sympathetic over activity [66].

There is a potential for clinical use of ghrelin in various circumstances. Current clinical studies are investigating the indications of ghrelin, which include cachexia in cancer, chronic obstructive pulmonary disease, chronic heart failure, end-stage renal failure, GI motility disorders (gastroparesis, functional dyspepsia and post-operative ileus), anorexia nervosa, GH deficiency, major depression and alcohol craving [67].

\section{Obestatin}

Obestatin is produced from the prohormone "preproghrelin" that also generates ghrelin. The name is derived from the Latin word "obedere" meaning "to devour", and "statin" meaning "suppression" as food intake was suppressed by obestatin [68]. Initially it was reported that obestatin could activate G-protein-coupled receptor GPR39 and suppress appetite and gastric emptying. In subsequent studies, these findings could not be confirmed by several investigators [69]. Obestatin is found in gastric mucosa, and its serum level is decreased in obesity but increased in anorexia nervosa [70]. Further studies are required to clarify the role of obestatin.

\section{GRP}

GRP is the mammalian homolog of bombesin (BN) which was originally isolated from the skin of two European amphibians, Bombina bombina and Bombina variegate [71]. GRP is present in the submucosa and myenteric plexuses of the stomach and intestine as well as in the intrapancreatic ganglia, hypothalamus and brain stem. The main function of GRP is to stimulate antral gastrin release from $G$ cells and increase acidity of the stomach. GRP is trophic to GI mucosa and pancreas. It works as a universal on-switch, and stimulates the secretion of most of the GI hormones, intestinal and pancreatic secretions, and regulates gut motility [72]. Normally GRP receptors (also known as BB2) are present in the stomach, pancreas, adrenal cortex and brain. Aberrantly, BB2 are also expressed in various cancers including stomach, colon, pancreas, breast, lung and prostate cancers. There are prospects for using radiolabeled and cytotoxic GRP analogues and antagonists for the diagnosis and treatment of cancers in the future [73].

\section{Gastric inhibitory peptide (GIP)}

GIP is a 42-amino acid peptide hormone released from the enteroendocrine $\mathrm{K}$ cells of the duodenal and jejunal mucosa in response to glucose, amino acids and fatty acids. In animal studies, GIP was found to inhibit food-stimulated secretion of gastrin along with gastrin-stimulated secretion of acid [74].

Although GIP has received its namesake from this functionality, its role on human gastrin and gastric acidity is less important. The most important function of GIP is now considered to be its ability to induce insulin secretion directly from the beta cells of pancreas during hyperglycemia. Oral ingestion of glucose causes more insulin release than intravenous administration of glucose, possibly due to hyperosmolarity of glucose in the duodenum [75]. GIP secretion occurs in a biphasic fashion at 5 and 45 min after ingestion of nutrients. Because of its "incretin" action, it is also called glucose-dependent insulinotropic polypeptide, thus keeping the same acronym GIP [76]. GIP not only promotes pancreatic beta cell proliferation but also stimulates glucagon secretion from $\alpha$ cells of islets of Langerhans of pancreas [77]. The incretin effect of GIP is much less in patients with diabetes mellitus [78]. GIP also stimulates lipoprotein lipase to release fatty acids from chylomicrons containing ingested fat and thus helps in fat deposition in the body. GIP also helps in bone formation by stimulating osteoblasts. This hormone is rapidly deactivated by the enzyme dipeptidyl peptidase 4 (DPP-4) in the blood [79].

\section{GLP-1}

GLP-1 is a 30-amino acid peptide hormone released from the enteroendocrine L cells present mainly in the distal ileum and colon, with some in the proximal small intestine [80], $\alpha$ cells of islets of Langerhans of pancreas [81] and GLP-1 neurons in the nucleus tractus solitaries of the brain stem [82]. GLP-1 and glucagon come from the same molecule called pre-proglucagon. GLP-1 acts as an endogenous incretin as it stimulates glucose-dependent release of insulin from the pancreas both in healthy persons and type II diabetic patients. It also causes the glucose-dependent inhibition of glucagon secretion (i.e. inhibition of post-prandial glucagon secretion) from $\alpha$ cells of pancreatic islets by $50 \%$ [83]. In contrast to GIP, only oral administration of glucose (not intravenous) stimulates secretion of GLP-1 in humans [84]. Ingestion of other sugars, dietary fibers, fatty acids and amino acids also stimulate GLP-1 secretion from L cells. Besides the contact of digested nutrients with L cells, there are neural and endocrine factors responsible for secretion of GLP-1. GLP-1 secretion occurs in a biphasic pattern: early phase within 10 - 15 min of ingestion followed by a second phase $30-60 \mathrm{~min}$ after ingestion. The early phase is probably due to endocrine and neural factors like GRP, GIP and acetylcholine whereas the late phase is due to direct contact of L cells with digested nutrients. GLP-1 has a short half-life of $2 \mathrm{~min}$ as it is quickly degraded by dipeptidyl peptidase IV (DPP-IV) and neural endopeptidase 24.11 in the circulation. In addition to the incretin function, GLP-1 induces 
pancreatic $\beta$ cell proliferation, delays gastric emptying, suppresses appetite and gives the sensation of fullness of stomach during and in between meals leading to loss of weight [85].

GLP-1 has therapeutic implications. 1) GLP-1-based therapies, i.e. GLP-1 mimetics are now used in our clinical practice in patients with type II diabetes mellitus. They include DPP-4-resistant GLP-1 agonists and DPP-4 inhibitors. GLP-1 agonists include liraglutide, exenatide and dulglutide. DPP-4 inhibitors include sitagliptin, saxagliptin, linagliptin and alogliptin. 2) GLP-1 mimetics could be a novel therapeutic agent in the treatment of non-alcoholic fatty liver disease (NAFLD) as it increases fatty acid oxidation, decreases lipogenesis and improves glucose metabolism in the liver [86]. Liraglutide led to greater resolution of non-alcoholic steatohepatitis (NASH) and less progression of fibrosis when given daily for 48 weeks in patients with non-alcoholic steatohepatitis [87]. GLP-1 mimetics are not yet recommended by the American Association for the Study of Liver Diseases (AASLD) specifically to treat NAFLD or NASH [88].

\section{GLP-2}

GLP-2 is a 33-amino acid peptide hormone secreted by the L cells in the distal small intestine and colon. GLP-2 is secreted after luminal contact of digested nutrients with L cells. There is biphasic release of GLP-2 after oral ingestion of food: initial release occurs within 15 min followed by a second release after $1 \mathrm{~h}$. GLP-2 is trophic to the mucosa of small intestine and colon as it induces cellular proliferation and inhibits proteolysis and apoptosis. GLP-2 suppresses gastric motility, gastric secretion and increases hexose transport activity [89].

GLP-2 has therapeutic implications. Teduglutide is a longacting recombinant analogue of human GLP-2. It is approved for the treatment of adult patients with SBS who are dependent on TPN. In a clinical study, those TPN-dependent SBS patients who received teduglutide had at least $20 \%$ reduction of TPN need from baseline at week 20, which was maintained at week $24[90]$.

\section{Glicentin}

Glicentin is a 69-amino acid peptide derived from proglucagon mainly produced in the intestinal L cells [91]. Other hormones processed from proglucagon include glucagon, oxyntomodulin, GLP-1 and GLP-2. Plasma levels of glicentin increase after nutrient ingestion. Although glicentin is a major gut glucagon, its functions still remain unknown.

\section{Gastric Leptin}

Gastric leptin is secreted from the gastric chief cells in the lower half of gastric glands and as well as from the specific endocrine cell types in exocrine and endocrine fashions, respectively. In contrast to adepokine leptin, gastric leptin is secreted in response to food intake [92]. It survives in the acidic environment of gastric juice by forming a complex with its soluble receptor in the secretory granules of chief cells and specific endocrine cells before being released into the gastric lumen. The soluble receptor is synthesized by gastric chief cells and endocrine cells. Leptin-leptin receptor complex then goes into the duodenum where leptin is actively taken in by the duodenocytes. Leptin again binds with its soluble receptor at the level of Golgi apparatus in duodenocytes, and then the newly formed leptin-leptin receptor complex is secreted baso-laterally into the intestinal mucosa to reach the circulation [93]. Both adepokine leptin and gastric leptin bind with receptors on the arcuate nucleus of hypothalamus in the brain. Gastric leptin controls short-term food intake independently whereas adepokine leptin regulates long-term food intake and increases metabolic rate to achieve energy balance. Leptin is an anorexigenic hormone also called the "satiety hormone" or the "hormone of energy expenditure". Leptin has diverse functions on the GI tract. These include delayed gastric emptying when leptin interacts with cholecystokinin and the vagus nerve, decreased absorption of carbohydrates, increased absorption of peptides in physiological states, gut mucosal cell proliferation and inhibition of apoptosis [94].

\section{Neurotensin}

Neurotensin is a 13-amino acid peptide hormone found in the GI tract and brain. In the brain, it acts as a neurotransmitter and regulates dopaminergic transmission and secretion of hormones from the anterior pituitary gland [95]. In the gut, it is secreted by the endocrine $\mathrm{N}$ cells present in the ileum and also in the enteric neurons of myenteric nerve plexus. Neurotensin secretion occurs after luminal contact with lipids. Neurotensin can cause GI smooth muscle contraction and stimulate gastric, intestinal and pancreatic secretions [96]. It can also decrease the lower esophageal sphincter pressure and inhibit the vagal stimulation of gastric acid and pepsin secretion [97]. Neurotensin stimulates colonic motility but decreases gastric and small bowel motility. It promotes the growth of small bowel and colonic mucosa [98].

Clinical implications: Neurotensin and neurotensin receptors can induce the activation of multiple oncogenic signaling pathways, including the PKC/ERK and AKT pathways. They are overexpressed in various cancers and aid their progression. These include colon, pancreatic, prostate, lung and breast cancer [99]. There is an unmet need for the development of active and safe antagonists for neurotensin and neurotensin receptors to treat these cancers.

\section{Substance P}

Substance $\mathrm{P}$ is an 11-amino acid neuropeptide widely distributed in the body with high concentrations in the central nervous system (CNS) and gut [100]. In the GI tract, it is found in the myenteric plexus and vagus nerves [101].

Substance $\mathrm{P}$ is a tachykinin and mediates its functions after binding with neurokinin-1 (NK-1) receptors which are 
widely distributed in the CNS, muscle cells and immune cells [102]. Substance $P$ has roles in various conditions which include nausea, vomiting, inflammation, hematopoiesis and allergy. High concentrations of substance P and NK-1 receptor are present in the vomiting center (area postrema) of medulla oblongata and activation of substance P may lead to nausea and vomiting. Aprepitant is a substance $\mathrm{P} / \mathrm{NK}-1$ receptor antagonist. It is used in chemotherapy-induced acute and delayed nausea and vomiting [103]. Another NK -1 receptor antagonist tradipitant has been found to be helpful in nausea and vomiting due to diabetic or idiopathic gastroparesis, and also in controlling chronic itching due to eczema. Secreted by inflammatory cells, substance $\mathrm{P}$ has pro-inflammatory properties and is involved in inflammatory disorders of the GI, respiratory and musculoskeletal systems [104]. Substance P receptors are found on hematopoietic cells and are involved in physiologic and malignant hematopoiesis [105]. In addition, substance P may decrease IgE-mediated allergy. One study showed decreased IgE-mediated reactivity when substance $\mathrm{P}$ and one allergen were given by aerosol delivery or injection to patients with reactivity to more than one allergen [106].

\section{Oxyntomodulin}

Oxyntomodulin is a 37-amino acid peptide derived from proglucagon. It is released in the post-prandial period from intestinal L cells. Oxtyntomodulin does not have its own receptor as it stimulates glucagon receptor and GLP-1 receptor. The hyperglycemic risk of activation of glucagon receptor is counteracted by the activation of GLP-1 receptor. Oxyntomodulin decreases food intake, accelerates energy expenditure and maintains glucose homoeostasis. Thus oxyntomodulin has therapeutic potential in obesity and type II diabetes mellitus [107].

\section{Uroguanylin}

Uroguanylin is a 16-amino acid peptid hormone released from the enterochromaffin cells of the duodenum and jejunum. It is released both into the gut lumen and circulation when the upper small bowel mucosa comes in contact with a high salt load [108]. Luminal uroguanylin binds to guanylate cyclaseC (GC-C) receptors located throughout the GI tract epithelium [109] and activates them. Activation of GC-C receptors leads to an increase in the intracellular concentration of cyclic guanosine monophosphate (GMP). Cyclic GMP then activates protein kinase which causes activation of cystic fibrosis transmembrane conductance regulator (CFTR) that results in the secretion of chloride and bicarbonate into the gut lumen. Activated protein kinase also inhibits sodium-hydrogen exchange leading to decreased absorption of sodium. The ultimate result is increased secretion of water and electrolytes into the gut lumen. GC-C receptor activation may reduce inflammation and pain sensation in the gut [110]. Uroguanylin preferentially activates $\mathrm{GC}-\mathrm{C}$ receptors in the duodenum and in more acidic environments.
Circulatory uroguanylin binds and activates GC-C receptors on the proximal convoluted tubules of kidney. It leads to increased intracellular concentration cyclic GMP and activation of protein kinase which increases sodium, potassium and water excretion in the urine [111]. Therefore, physiologically, uroguanylin controls not only stool consistency and bowel function but also fluid and electrolyte balance in the body.

Clinical and therapeutic implications: $\mathrm{GC}-\mathrm{C}$ receptors are activated not only by endogenous uroguanylin and guanylin but also by bacterial heat-stable enterotoxin seen in traveler's diarrhea, and the synthetic products linaclotide, plecanatide and dolcanatide [112]. Linaclotide and plecanatide are used in irritable bowel syndrome with predominant constipation (IBSC) and chronic idiopathic constipation (CIC). Dolcanatide is still being investigated in clinical trials to find out its efficacy in mild to moderate ulcerative colitis [113].

Dysregulation of GC-2C-cGMP signaling may have roles in the pathogenesis of inflammatory bowel disease, bowel transit disorders and colorectal cancers.

The sources of different GI hormones with their diagnostic and therapeutic roles are mentioned in Table 2.

\section{Summary}

The GI tract is the largest endocrine organ of the body and is the hub of many hormones. They have many physiologic functions essential for our digestion and absorption of nutrients, GI motility and secretions, while having trophic effects on the GI mucosa and pancreas. They contribute to our feeling of hunger and satiety, control of our appetite and body weight, glucose homoeostasis, fluid and electrolyte balance of our body, and our physical and mental health.

There are numerous GI hormones with both unique and overlapping functions. Ghrelin increases appetite and gastric leptin suppresses appetite. Gastrin increases gastric acidity. Pepsin breaks down protein into peptides. Cholecystokinin stimulates gallbladder contraction, pancreatic enzyme secretion and small bowel motility. Secretin stimulates bicarbonate rich pancreatic secretion. Somatostatin inhibits the secretion of multiple hormones (GH, TSH, ACTH, gastrin, CCK, secretin, insulin and glucagon) and gastric, intestinal and pancreatic secretions, while also reducing portal and splanchnic blood flow. Motilin stimulates GI motility and pepsin secretion. GRP stimulates gastrin secretion as well as intestinal and pancreatic secretions. GIP inhibits gastrin secretion but stimulates insulin and glucagon secretion. GLP-1 stimulates glucose-dependent insulin secretion. GLP-2 is trophic to the mucosa of small intestine and colon. Neurotensin increases the motility of colon but decreases the motility of stomach and small intestine. Substance P stimulates the vomiting center in the brain stem. Oxyntomodulin helps in maintaining blood glucose. Uroguanylin stimulates water and electrolyte secretion into the gut to control stool consistency and also maintains fluid and electrolyte balance in our body by natriuresis, kaliuresis and diuresis.

Specific GI hormones are utilized in different diagnostic tests. These include the secretin suppression test to diagnose 


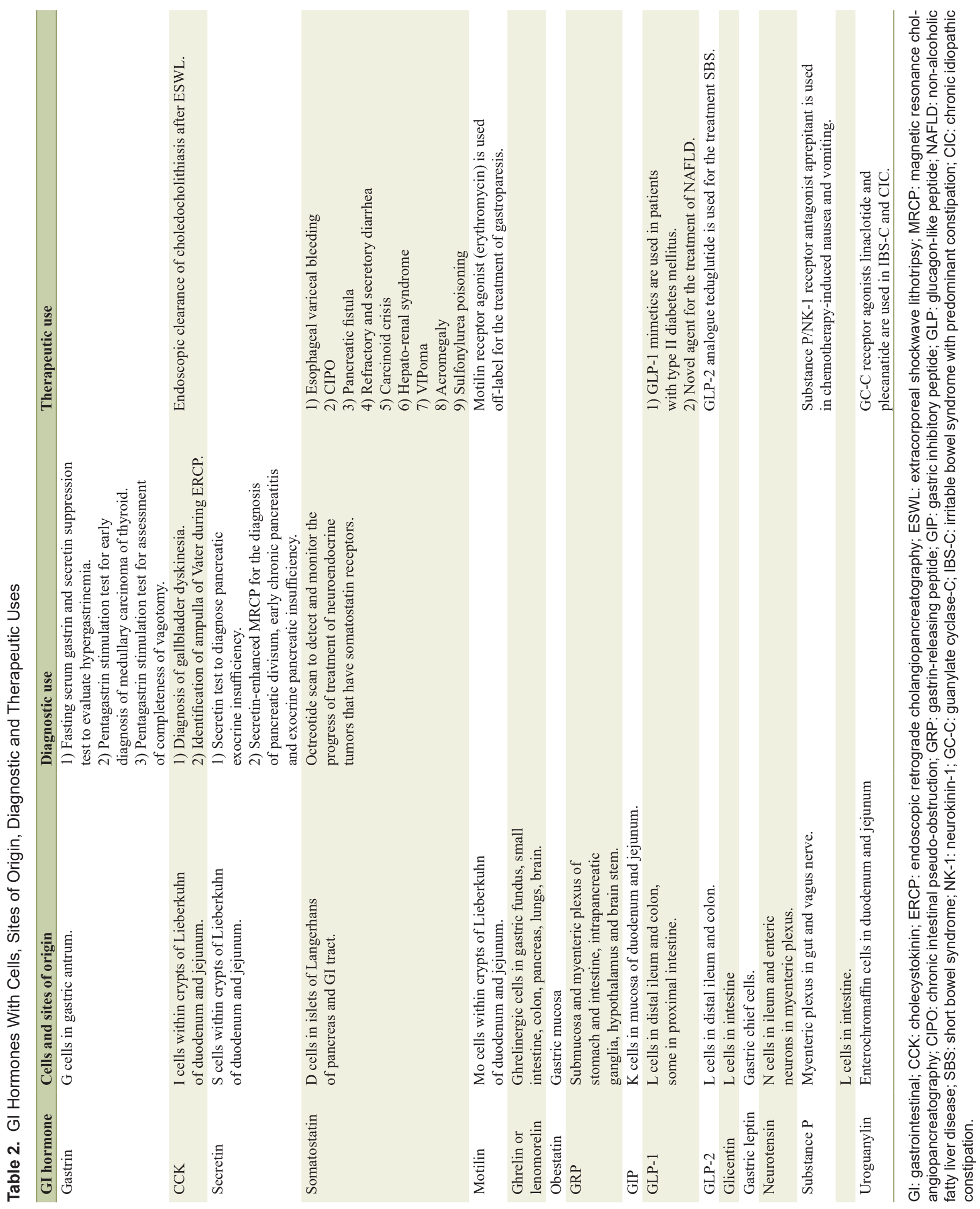


gastrinoma, the pentagastrin test to diagnose medullary carcinoma of thyroid gland the HIDA scan with CCK to measure EF of the gall bladder, the secretin test to diagnose pancreatic exocrine insufficiency, the secretin-enhanced MRCP to diagnose pancreatic divisum and the octreotide scan to detect somatostatin receptor positive neuroendocrine tumors.

GI hormones can be therapeutic in different disease states. These include the use of octreotide in esophageal variceal bleeding, intestinal pseudoobstruction, pancreatic fistula, secretory diarrhea, carcinoid syndrome, carcinoid crisis, HRS, VIPoma, acromegaly and sulfonylurea poisoning. The motilin agonist erythromycin is used off-label in patients with gastroparesis. GLP-1 agonists and DPP-4 inhibitors are used in type II diabetes mellitus and could also be used as novel forms of therapy for patients with NAFLD and diabetes mellitus. The GLP-2 agonist teduglutide is used in patients with TPNdependent SBS. The substance $\mathrm{P} / \mathrm{NK}-1$ receptor antagonist aprepitant is used in chemotherapy-induced acute and delayed nausea and vomiting. The uroguanylin analogues linaclotide and plecanatide are used in IBS-C and CIC.

GI hormones can have multiple sources. Gastrin is secreted from the stomach, duodenum, pancreas and pituitary gland. Somatostatin is secreted from hypothalamus, pancreas and GI tract. Ghrelin is secreted from stomach, small intestine, colon, pancreas, lungs and brain. GRP is secreted from stomach, intestine, intrapancreatic gangion, hypothalamus and brain stem. Substance P and neurotensin are secreted from the GI tract and brain.

Some of the gut hormones help to proliferate normal tissue. Gastrin is trophic to gastric mucosa; CCK and GRP are trophic to GI mucosa and pancreas; and GLP-2 and neurotensin are trophic to small intestinal mucosa and colon. On the other hand, somatostatin inhibits growth of GI tract and pancreas. Some hormonal receptors are overexpressed in different malignancies: CCKBR in gastric, colon and pancreatic cancer; GRP receptors in cancers of stomach, pancreas, adrenal cortex and brain; and neurotensin receptors in colon, pancreatic, prostate, lung and breast cancer.

There is an unmet need for the development of antagonists or agents against those receptors to treat cancers. Further research should be done to find out other potential diagnostic and therapeutic roles of GI hormones.

\section{Acknowledgments}

None to declare.

\section{Financial Disclosure}

None to declare.

\section{Conflict of Interest}

Monjur Ahmed and Sarah Ahmed declare that they have no conflict of interest.

\section{Author Contributions}

Each author has reviewed the final version of the manuscript and approves it for publication.

\section{References}

1. Rao JN, Wang JY. In: Regulation of gastrointestinal mucosal growth. San Rafael (CA). 2010.

2. Thomas RP, Hellmich MR, Townsend CM, Jr., Evers BM. Role of gastrointestinal hormones in the proliferation of normal and neoplastic tissues. Endocr Rev. 2003;24(5):571-599.

3. Vella A, Drucker DJ. Chapter 39. Gastrointestinal Hormones and Gut Endocrine Tumors. In: Williams Textbook of Endocrinology, 12th edition. 2011:1697-1707.

4. Larsson L, Rehfeld JF. A peptide resembling COOH-terminal tetrapeptide amide of gastrin from a new gastrointestinal endocrine cell type. Nature. 1979;277(5697):575578.

5. Bardram L, Hilsted L, Rehfeld JF. Progastrin expression in mammalian pancreas. Proc Natl Acad Sci U S A. 1990;87(1):298-302.

6. Rehfeld JF. The expression of progastrin, procholecystokinin and their hormonal products in pituitary cells. J Mol Endocrinol. 1988;1(2):87-94.

7. Merali Z, McIntosh J, Anisman H. Role of bombesinrelated peptides in the control of food intake. Neuropeptides. 1999;33(5):376-386.

8. Schubert ML, Makhlouf GM. Neural, hormonal, and paracrine regulation of gastrin and acid secretion. Yale $\mathrm{J}$ Biol Med. 1992;65(6):553-560; discussion 621-553.

9. Haruma K, Kamada T, Manabe N, Suehiro M, Kawamoto H, Shiotani A. Old and New Gut Hormone, Gastrin and Acid Suppressive Therapy. Digestion. 2018;97(4):340344.

10. Sekiguchi T. Gastrin. In: Takei Y, Ando H, Tsutsui K. Handbook of hormones. 2016:174. ISBN: 978-0-12801028-0.

11. Correa P. Serum pepsinogens in gastric cancer screening. Dig Dis Sci. 2010;55(8):2123-2125.

12. Mortensen NJ. The anatomy of the gastrin cell. Ann R Coll Surg Engl. 1980;62(6):462-469.

13. Rogers K. Gastrin Hormone. Encyclopaedia Britannica. https://www.britannica.com/science/gastrin.

14. Yang RH, Chu YK. Zollinger-Ellison syndrome: Revelation of the gastrinoma triangle. Radiol Case Rep. 2015;10(1):827.

15. Frucht H, Doppman JL, Norton JA, Miller DL, Dwyer AJ, Frank JA, Vinayek R, et al. Gastrinomas: comparison of MR imaging with CT, angiography, and US. Radiology. 1989;171(3):713-717.

16. Ruszniewski P, Amouyal P, Amouyal G, Grange JD, Mignon M, Bouche O, Bernades P. Localization of gastrinomas by endoscopic ultrasonography in patients with Zollinger-Ellison syndrome. Surgery. 1995;117(6):629635. 
17. Dacha S, Razvi M, Massaad J, Cai Q, Wehbi M. Hypergastrinemia. Gastroenterol Rep (Oxf). 2015;3(3):201208.

18. Bradley EL, 3rd, Galambos JT. Diagnosis of gastrinoma by the secretin suppression test. Surg Gynecol Obstet. 1976;143(5):784-788.

19. Petersen H, Myren J. Pentagastrin dose-response in peptic ulcer disease. Scand J Gastroenterol. 1975;10(7):705714.

20. Hirschowitz BI. Apparent and intrinsic sensitivity to pentagastrin of acid and pepsin secretion in peptic ulcer. Gastroenterology. 1984;86(5 Pt 1):843-851.

21. Machens A, Hauptmann S, Dralle H. Medullary thyroid cancer responsiveness to pentagastrin stimulation: an early surrogate parameter of tumor dissemination? J Clin Endocrinol Metab. 2008;93(6):2234-2238.

22. Barbot N, Calmettes C, Schuffenecker I, Saint-Andre JP, Franc B, Rohmer V, Jallet P, et al. Pentagastrin stimulation test and early diagnosis of medullary thyroid carcinoma using an immunoradiometric assay of calcitonin: comparison with genetic screening in hereditary medullary thyroid carcinoma. J Clin Endocrinol Metab. 1994;78(1):114-120.

23. Ball DW. Medullary thyroid cancer. In: Wondisford F, Radovick S. Clinical management of thyroid disease. 2009. ISBN. 978-1-4160-4745-2.

24. Gobet B, Malikova E, Mignon M, Vatier J. Gastric secretory investigation of recurrent ulcer after surgery for duodenal ulcer. Hepatogastroenterology. 1991;38(6):522527.

25. Chandra R, Liddle RA. Cholecystokinin. Curr Opin Endocrinol Diabetes Obes. 2007;14(1):63-67.

26. Riyad K, Chalmers CR, Aldouri A, Fraser S, Menon K, Robinson PJ, Toogood GJ. The role of (99m)technetium-labelled hepato imino diacetic acid (HIDA) scan in the management of biliary pain. HPB (Oxford). 2007;9(3):219-224.

27. Tao T, Zhang QJ, Zhang M, Zhu X, Sun SX, Li YQ. Using cholecystokinin to facilitate endoscopic clearance of large common bile duct stones. World J Gastroenterol. 2014;20(29):10121-10127.

28. Gomez GA, Englander EW, GreeleyJr GH. Postpyloric Gastrointestinal Peptides. In: Johnson LR, Ghishan FK, Wood JK. Physiology of the gastrointestinal tract (Fifth Edition). 2012;1:155-198. ISBN: 978-0-12-382026-6.

29. https://www.britannica.com/science/secretin.

30. Dreiling DA. Pancreatic secretory testing in 1974. Gut. 1975;16(8):653-657.

31. Moolsintong P, Burton FR. Pancreatic function testing is best determined by the extended endoscopic collection technique. Pancreas. 2008;37(4):418-421.

32. Czako L, Endes J, Takacs T, Boda K, Lonovics J. Evaluation of pancreatic exocrine function by secretin-enhanced magnetic resonance cholangiopancreatography. Pancreas. 2001;23(3):323-328.

33. Matos C, Metens T, Deviere J, Delhaye M, Le Moine O, Cremer M. Pancreas divisum: evaluation with secretinenhanced magnetic resonance cholangiopancreatography. Gastrointest Endosc. 2001;53(7):728-733.
34. Brown JC. "Enterogastrone" and other new gut peptides. Med Clin North Am. 1974;58(6):1347-1358.

35. Bishop AE, Polak JM, Bloom SR. Gastrointestinal hormones. In: Mutt V. Advances in metabolic disorders. 1988;11:1-508. ISBN: 978-0-12-027311-9.

36. Reichlin S. Somatostatin (second of two parts). N Engl J Med. 1983;309(25):1556-1563.

37. Kwekkeboom DJ, Krenning EP. Somatostatin receptor imaging. Semin Nucl Med. 2002;32(2):84-91.

38. Ansari P. Varices. Gastrointestinal bleeding. Merck's Manual. www.merckmanuals.com.

39. Corley DA, Cello JP, Adkisson W, Ko WF, Kerlikowske K. Octreotide for acute esophageal variceal bleeding: a meta-analysis. Gastroenterology. 2001;120(4):946-954.

40. Vorobioff JD, Ferretti SE, Zangroniz P, Gamen M, Picabea E, Bessone FO, Reggiardo V, et al. Octreotide enhances portal pressure reduction induced by propranolol in cirrhosis: a randomized, controlled trial. Am J Gastroenterol. 2007;102(10):2206-2213.

41. Verne GN, Eaker EY, Hardy E, Sninsky CA. Effect of octreotide and erythromycin on idiopathic and scleroderma-associated intestinal pseudoobstruction. Dig Dis Sci. 1995;40(9):1892-1901.

42. Soudah HC, Hasler WL, Owyang C. Effect of octreotide on intestinal motility and bacterial overgrowth in scleroderma. N Engl J Med. 1991;325(21):1461-1467.

43. Ambartsumyan L, Flores A, Nurko S, Rodriguez L. Utility of Octreotide in Advancing Enteral Feeds in Children with Chronic Intestinal Pseudo-Obstruction. Paediatr Drugs. 2016;18(5):387-392.

44. Barnes SM, Kontny BG, Prinz RA. Somatostatin analog treatment of pancreatic fistulas. Int J Pancreatol. 1993;14(2):181-188.

45. Farthing MJ. Octreotide in the treatment of refractory diarrhoea and intestinal fistulae. Gut. 1994;35(3 Suppl):S5-10.

46. Harris AG, O'Dorisio TM, Woltering EA, Anthony LB, Burton FR, Geller RB, Grendell JH, et al. Consensus statement: octreotide dose titration in secretory diarrhea. Diarrhea Management Consensus Development Panel. Dig Dis Sci. 1995;40(7):1464-1473.

47. Goumas P, Naxakis S, Christopoulou A, Chrysanthopoulos C, Nikolopoulou VV, Kalofonos HP. Octreotide acetate in the treatment of fluorouracil-induced diarrhea. Oncologist. 1998;3(1):50-53.

48. Seymour N, Sawh SC. Mega-dose intravenous octreotide for the treatment of carcinoid crisis: a systematic review. Can J Anaesth. 2013;60(5):492-499.

49. Vinik AI, Wolin EM, Liyanage N, Gomez-Panzani E, Fisher GA, * ESG. Evaluation of Lanreotide Depot/Autogel Efficacy and Safety as a Carcinoid Syndrome Treatment (Elect): A Randomized, Double-Blind, PlaceboControlled Trial. Endocr Pract. 2016;22(9):1068-1080.

50. Hecker R, Sherlock S. Electrolyte and circulatory changes in terminal liver failure. Lancet. 1956;271(6953):11211125.

51. Salerno F, Gerbes A, Gines P, Wong F, Arroyo V. Diagnosis, prevention and treatment of hepatorenal syndrome in cirrhosis. Gut. 2007;56(9):1310-1318. 
52. Esrailian E, Pantangco ER, Kyulo NL, Hu KQ, Runyon BA. Octreotide/Midodrine therapy significantly improves renal function and 30-day survival in patients with type 1 hepatorenal syndrome. Dig Dis Sci. 2007;52(3):742-748.

53. Adam N, Lim SS, Ananda V, Chan SP. VIPoma syndrome: challenges in management. Singapore Med J. 2010;51(7):e129-132.

54. Song S, Shi R, Li B, Liu Y. Diagnosis and treatment of pancreatic vasoactive intestinal peptide endocrine tumors. Pancreas. 2009;38(7):811-814.

55. Elshafie O, Grant C, Al-Hamdani A, Jain R, Woodhouse N. VIPoma Crisis: Immediate and life saving reduction of massive stool volumes on starting treatment with octreotide. Sultan Qaboos Univ Med J. 2011;11(1):104-107.

56. Thapar K, Kovacs KT, Stefaneanu L, Scheithauer BW, Horvath E, Lloyd RV, Li J, et al. Antiproliferative effect of the somatostatin analogue octreotide on growth hormone-producing pituitary tumors: results of a multicenter randomized trial. Mayo Clin Proc. 1997;72(10):893-900.

57. McLaughlin SA, Crandall CS, McKinney PE. Octreotide: an antidote for sulfonylurea-induced hypoglycemia. Ann Emerg Med. 2000;36(2):133-138.

58. Daniel EE. Neuropeptide function in the gastrointestinal tract. CRC Press.1990:357. ISBN: 9780849361586.

59. Poitras P, Peeters TL. Motilin. Curr Opin Endocrinol Diabetes Obes. 2008;15(1):54-57.

60. Fiorucci S, Morelli A. Motilin and erythromycin stimulate pepsinogen secretion by chief cells isolated from guinea pig stomach. Gastroenterology. 1993;104(4):1030-1036.

61. Luiking YC, Peeters TL, Stolk MF, Nieuwenhuijs VB, Portincasa P, Depoortere I, van Berge Henegouwen GP, et al. Motilin induces gall bladder emptying and antral contractions in the fasted state in humans. Gut. 1998;42(6):830-835.

62. Peeters T, Matthijs G, Depoortere I, Cachet T, Hoogmartens J, Vantrappen G. Erythromycin is a motilin receptor agonist. Am J Physiol. 1989;257(3 Pt 1):G470474.

63. Sturm A, Holtmann G, Goebell H, Gerken G. Prokinetics in patients with gastroparesis: a systematic analysis. Digestion. 1999;60(5):422-427.

64. Camilleri M, Parkman HP, Shafi MA, Abell TL, Gerson L, American College of G. Clinical guideline: management of gastroparesis. Am J Gastroenterol. 2013;108(1):18-37; quiz 38 .

65. Sakata I, Sakai T. Ghrelin cells in the gastrointestinal tract. Int J Pept. 2010;2010:945056.

66. Pradhan G, Samson SL, Sun Y. Ghrelin: much more than a hunger hormone. Curr Opin Clin Nutr Metab Care. 2013;16(6):619-624.

67. Strasser F. Clinical application of ghrelin. Curr Pharm Des. 2012;18(31):4800-4812.

68. Zhang JV, Ren PG, Avsian-Kretchmer O, Luo CW, Rauch R, Klein C, Hsueh AJ. Obestatin, a peptide encoded by the ghrelin gene, opposes ghrelin's effects on food intake. Science. 2005;310(5750):996-999.

69. Ren G, He Z, Cong P, Chen H, Guo Y, Yu J, Liu Z, et al. Peripheral administration of TAT-obestatin can influence the expression of liporegulatory genes but fails to affect food intake in mice. Peptides. 2013;42:8-14.

70. Seim I, Walpole C, Amorim L, Josh P, Herington A, Chopin L. The expanding roles of the ghrelin-gene derived peptide obestatin in health and disease. Mol Cell Endocrinol. 2011;340(1):111-117.

71. Spindel ER, Bombesin peptides. In: Kastin AJ. Handbook of biologically active peptides (Second Edition). 2013. ISBN: 978-0-12-385095-9.

72. West SD, Mercer DW. Bombesin-induced gastroprotection. Ann Surg. 2005;241(2):227-231.

73. Patel O, Shulkes A, Baldwin GS. Gastrin-releasing peptide and cancer. Biochim Biophys Acta. 2006;1766(1):2341.

74. Villar HV, Fender HR, Rayford PL, Bloom SR, Ramus NI, Thompson JC. Suppression of gastrin release and gastric secretion by gastric inhibitory polypeptide (GIP) and vasoactive intestinal polypeptide (VIP). Ann Surg. 1976;184(1):97-102.

75. Thorens B. Glucagon-like peptide-1 and control of insulin secretion. Diabete Metab. 1995;21(5):311-318.

76. Pederson RA, McIntosh CH. Discovery of gastric inhibitory polypeptide and its subsequent fate: Personal reflections. J Diabetes Investig. 2016;7(Suppl 1):4-7.

77. Tura A, Pacini G, Yamada Y, Seino Y, Ahren B. Glucagon and insulin secretion, insulin clearance, and fasting glucose in GIP receptor and GLP-1 receptor knockout mice. Am J Physiol Regul Integr Comp Physiol. 2019;316(1):R27-R37.

78. Nauck MA, Meier JJ. Incretin hormones: Their role in health and disease. Diabetes Obes Metab. 2018;20(Suppl 1):5-21.

79. GIP (Gastric Inhibitory Polypeptide) - Pacific Biomarkers. https://pacbio.com/biomarker/assay-detail/28/.

80. Baggio LL, Drucker DJ. Biology of incretins: GLP-1 and GIP. Gastroenterology. 2007;132(6):2131-2157.

81. Graaf C, Donnelly D, Wootten D, Lau J, Sexton PM, Miller LJ, Ahn JM, et al. Glucagon-like peptide-1 and its Class B G protein-coupled receptors: a long march to therapeutic successes. Pharmacol Rev. 2016;68(4):9541013.

82. Alhadeff AL, Rupprecht LE, Hayes MR. GLP-1 neurons in the nucleus of the solitary tract project directly to the ventral tegmental area and nucleus accumbens to control for food intake. Endocrinology. 2012;153(2):647-658.

83. Manandhar B, Ahn JM. Glucagon-like peptide-1 (GLP-1) analogs: recent advances, new possibilities, and therapeutic implications. J Med Chem. 2015;58(3):1020-1037.

84. Herrmann C, Goke R, Richter G, Fehmann HC, Arnold R, Goke B. Glucagon-like peptide-1 and glucose-dependent insulin-releasing polypeptide plasma levels in response to nutrients. Digestion. 1995;56(2):117-126.

85. Kanoski SE, Hayes MR, Skibicka KP. GLP-1 and weight loss: unraveling the diverse neural circuitry. Am J Physiol Regul Integr Comp Physiol. 2016;310(10):R885-895.

86. Lee J, Hong SW, Rhee EJ, Lee WY. GLP-1 Receptor Agonist and Non-Alcoholic Fatty Liver Disease. Diabetes Metab J. 2012;36(4):262-267.

87. Armstrong MJ, Gaunt P, Aithal GP, Barton D, Hull D, Parker R, Hazlehurst JM, et al. Liraglutide safety and efficacy 
in patients with non-alcoholic steatohepatitis (LEAN): a multicentre, double-blind, randomised, placebo-controlled phase 2 study. Lancet. 2016;387(10019):679-690.

88. Chalasani N, Younossi Z, Lavine JE, Charlton M, Cusi K, Rinella M, Harrison SA, et al. The diagnosis and management of nonalcoholic fatty liver disease: Practice guidance from the American Association for the study of liver diseases. Hepatology. 2018;67(1):328-357.

89. Burrin DG, Petersen Y, Stoll B, Sangild P. Glucagon-like peptide 2: a nutrient-responsive gut growth factor. J Nutr. 2001;131(3):709-712.

90. Burness CB, McCormack PL. Teduglutide: a review of its use in the treatment of patients with short bowel syndrome. Drugs. 2013;73(9):935-947.

91. Raffort J, Lareyre F, Massalou D, Fenichel P, Panaia-Ferrari $\mathrm{P}$, Chinetti $\mathrm{G}$. Insights on glicentin, a promising peptide of the proglucagon family. Biochem Med (Zagreb). 2017;27(2):308-324.

92. Pico C, Oliver P, Sanchez J, Palou A. Gastric leptin: a putative role in the short-term regulation of food intake. Br J Nutr. 2003;90(4):735-741.

93. Cammisotto P, Bendayan M. A review on gastric leptin: the exocrine secretion of a gastric hormone. Anat Cell Biol. 2012;45(1):1-16.

94. Yarandi SS, Hebbar G, Sauer CG, Cole CR, Ziegler TR. Diverse roles of leptin in the gastrointestinal tract: modulation of motility, absorption, growth, and inflammation. Nutrition. 2011;27(3):269-275.

95. Vincent JP, Mazella J, Kitabgi P. Neurotensin and neurotensin receptors. Trends Pharmacol Sci. 1999;20(7):302309.

96. Gomez GA, Englander EW, GreeleyJr GH. Postpyloric gastrointestinal peptides. In: Johnson LR, Ghishan FK, kaunitz JD, et al. Physiology of the Gastrointestinal Tract (Fifth Edition). 2012;1:155-198. ISBN 978-0-12-3820266.

97. https://www.britannica.com/science/neurotensin.

98. Yoshinaga K, Evers BM, Izukura M, Parekh D, Uchida T, Townsend CM, Jr., Thompson JC. Neurotensin stimulates growth of colon cancer. Surg Oncol. 1992;1(2):127-134.

99. Wu Z, Martinez-Fong D, Tredaniel J, Forgez P. Neurotensin and its high affinity receptor 1 as a potential pharmacological target in cancer therapy. Front Endocrinol (Lausanne). 2012;3:184.

100. Schwarz MJ, Ackenheil M. The role of substance P in depression: therapeutic implications. Dialogues Clin Neurosci. 2002;4(1):21-29.

101. Mantyh PW. Neurobiology of substance P and the NK1 receptor. J Clin Psychiatry. 2002;63(Suppl 11):6-10.

102. Kavelaars A, Broeke D, Jeurissen F, Kardux J, Meijer A, Franklin R, Gelfand EW, et al. Activation of human monocytes via a non-neurokinin substance $\mathrm{P}$ receptor that is coupled to $\mathrm{Gi}$ protein, calcium, phospholipase D, MAP kinase, and IL-6 production. J Immunol. 1994;153(8):3691-3699.

103. Prommer E. Aprepitant (EMEND): the role of substance $\mathrm{P}$ in nausea and vomiting. J Pain Palliat Care Pharmacother. 2005;19(3):31-39.

104. O'Connor TM, O'Connell J, O'Brien DI, Goode T, Bredin $\mathrm{CP}$, Shanahan F. The role of substance $\mathrm{P}$ in inflammatory disease. J Cell Physiol. 2004;201(2):167-180.

105. Nowicki M, Ostalska-Nowicka D, Kondraciuk B, Miskowiak B. The significance of substance $\mathrm{P}$ in physiological and malignant haematopoiesis. J Clin Pathol. 2007;60(7):749-755.

106. Patterson R, Harris KE, Grammer LC, Greenberger PA, Ditto AM, Shaughnessy MA. Potential effect of the administration of substance $\mathrm{P}$ and allergen therapy on immunoglobulin E-mediated allergic reactions in human subjects. J Lab Clin Med. 1999;133(2):189-199.

107. Pocai A. Action and therapeutic potential of oxyntomodulin. Mol Metab. 2014;3(3):241-251.

108. Seidler U, Sjoblom M. Role of the Guanylins in Duodenal HCO3- Secretion. In: Johnson LR, Kaunitz JD, Said HM, et al. Physiology of the Gastrointestinal Tract (Fifth Edition). ISBN: 978-0-12-382026-6.

109. Krause WJ, Cullingford GL, Freeman RH, Eber SL, Richardson KC, Fok KF, Currie MG, et al. Distribution of heat-stable enterotoxin/guanylin receptors in the intestinal tract of man and other mammals. J Anat. 1994;184(Pt 2):407-417.

110. Silos-Santiago I, Hannig G, Eutamene H, Ustinova EE, Bernier SG, Ge P, Graul C, et al. Gastrointestinal pain: unraveling a novel endogenous pathway through uroguanylin/guanylate cyclase-C/cGMP activation. Pain. 2013;154(9):1820-1830.

111. Forte LR, Fan X, Hamra FK. Salt and water homeostasis: uroguanylin is a circulating peptide hormone with natriuretic activity. Am J Kidney Dis. 1996;28(2):296-304.

112. Rappaport JA, Waldman SA. The guanylate cyclase CcGMP signaling axis opposes intestinal epithelial injury and neoplasia. Front Oncol. 2018;8:299.

113. Semedo D. Clinical trial for treatment of ulcerative colitis get positive report. IBD News Today. 2016; https:// ibdnewstoday.com/2016/02/18/clinical-trial-treatmentulcerative-colitis-gets-positive-report. 